Check for updates

Cite this: RSC Adv., 2017, 7, 29611

\title{
Layered manganese-based metal-organic framework as a high capacity electrode material for supercapacitors $\dagger$
}

\begin{abstract}
Xianmei Wang, ${ }^{a}$ Xiuxiu Liu, ${ }^{a}$ Hongren Rong, ${ }^{a}$ Yidan Song, ${ }^{a}$ Hao Wen ${ }^{a}$ and Qi Liu (DD *ab
For the development of supercapacitors with higher energy densities, metal-organic frameworks (MOFs), as electrode materials for supercapacitors, have attracted much attention. Herein, layered manganesebased MOF ([Mn(tfbdc)(4,4'-bpy)( $\left.\left.\mathrm{H}_{2} \mathrm{O}\right)_{2}\right], \mathrm{Mn}-\mathrm{LMOF} ; \mathrm{H}_{2} \mathrm{tfbdc}=$ 2,3,5,6-tetrafluoroterephthalic acid, 4,4'bpy $=4,4^{\prime}$-bipyridine) was synthesized by a simple solution reaction and evaluated as an electrode material for supercapacitors for the first time. The Mn-LMOF electrode showed a high specific capacitance, a good cycling stability and a improved rate capability. Its maximum specific capacitances were $1098 \mathrm{~F} \mathrm{~g}^{-1}$ for $1 \mathrm{M} \mathrm{KOH}$ and $1178 \mathrm{~F} \mathrm{~g}^{-1}$ for $1 \mathrm{M} \mathrm{LiOH}$ solutions at a current density of $1 \mathrm{~A} \mathrm{~g}^{-1}$. The specific capacitance retention was maintained at $92.6 \%$ after 2000 cycles in $1 \mathrm{M} \mathrm{KOH}$, slightly lower than that in $1 \mathrm{M} \mathrm{LiOH}$. The excellent supercapacitive performance may be ascribed to the nature of $\mathrm{Mn}$ LMOF, containing a layered structure and nano-sized particles.
\end{abstract}

Received 18th April 2017 Accepted 24th May 2017

DOI: $10.1039 / \mathrm{c} 7 \mathrm{ra0} 4374 \mathrm{k}$

rsc.li/rsc-advances route is to make hybrid composites by combining pure $\mathrm{MnO}_{x}$ and carbon materials, other metal oxides and conducting polymers. ${ }^{\mathbf{1 1 - 1 3}}$ The other is to design and synthesize new Mnbased electrode materials with high capacitance. Compared with that of pure $\mathrm{MnO}_{x}$, electrical conductivities of the hybrid composites were enhanced, but some new shortages, such as increase of inherent contact resistances, structural instability and decrease of capacitance appeared at the same time. Therefore, to solve these problems, it is necessary to use the route of preparing new Mn-based electrode materials with high capacitance.

Metal-organic frameworks (MOFs), as a class of porous coordination polymer materials, ${ }^{\mathbf{1 4 , 1 5}}$ have the advantages of high specific surface area, adjustable pore size, open metal sites and regular structure. Based on these advantages, they have potential applications in various fields, such as catalysis, ${ }^{16-18}$ gas capture and release, ${ }^{19,20}$ imaging and sensing, ${ }^{21,22}$ batteries, ${ }^{23-25}$ and magnetic materials. ${ }^{26}$ In recent years, the application research of MOFs in supercapacitors has seen rapid development. ${ }^{27-30}$ MOFs used as electrode materials of supercapacitors can be mainly ascribed to two major cases. In one case, MOFs are used as templates for synthesizing porous metal oxides, carbon or metal oxide/carbon composites. ${ }^{31,32}$ In the other case, pristine MOFs can directly act as electrode materials for supercapacitors, owing to their tunable pore size and metal ions with redox activity. ${ }^{33-57}$ To the best of our knowledge, in 2012, Díaz et al. first reported that Co8-MOF-5 $\left(\mathrm{Zn}_{3.68} \mathrm{Co}_{0.32} \mathrm{O}(\mathrm{BDC})_{3}(-\right.$ $\mathrm{DEF})_{0.75}$ ) can be directly used as the electrode material of supercapacitors ${ }^{33}$ in the same year, a Co-based MOF with threedimensional (3D) structure was investigated by Lee et al. as an electrode material for supercapacitors, which displayed 
a specific capacitance of $206 \mathrm{~F} \mathrm{~g}^{-1}$ in $\mathrm{LiOH}$ solution. ${ }^{34}$ Subsequently, dozens of MOF-based supercapacitor electrode materials have been reported in the past few years, such as, Co-based MOF ${ }^{35-39}$ zirconium-based MOF, ${ }^{40,41}$ Zn-based MOF ${ }^{42}$ and Nibased MOF. ${ }^{43-51}$ It is worthwhile to point out that our and Wei's groups have recently verified that two-dimensional (2D) layered MOFs can serve as high performance supercapacitor electrode materials. For example, in 2014, Wei et al. reported that a layered Ni-MOF can be used as a supercapacitor electrode material. This material showed a specific capacitance of $1127 \mathrm{~F}$ $\mathrm{g}^{-1}$ in $\mathrm{KOH}$ solution, an excellent cycling stability and a high rate capability. ${ }^{43}$ After Zn doping, the as-synthesized Zn-doped Ni-MOF exhibited an improved performance. ${ }^{44}$ In 2015 , we reported the synthesis of a layered Cu-MOF and investigated its capacitive behavior, which displayed a high specific capacitance of $1274 \mathrm{~F} \mathrm{~g} \mathrm{~g}^{-1}$ in LiOH solution. ${ }^{54}$ Subsequently, we evaluated a layered Co-MOF as a supercapacitor electrode material. This material can deliver a maximum specific capacitance of $2474 \mathrm{~F}$ $\mathrm{g}^{-1}$ at $1 \mathrm{~A} \mathrm{~g}^{-1} \cdot{ }^{38}$ In addition, Ni-MOF/carbon nanotube (CNT) composites were synthesized by Wen et al., which exhibited a better performance. ${ }^{47}$ Very recently, layered structural Co-MOF nanosheets were investigated by Wei et al. as an electrode material for supercapacitors, which showed a maximum specific capacitance of $2564 \mathrm{~F} \mathrm{~g}^{-1}$ at $1 \mathrm{~A} \mathrm{~g}^{-1} \cdot{ }^{39}$ Dină et al. utilized a layered, conductive Ni-MOF as an electrode material for supercapacitors. An areal capacitance of $18 \mathrm{mF} \mathrm{cm}^{-2}$ and capacity retention greater than $90 \%$ over 10000 cycles can be obtained in the conductive Ni-MOF-based device. In particular, this is the first example of a supercapacitor made entirely from neat MOFs as active materials, without conductive additives or other binders. ${ }^{50}$ The excellent electrochemical properties of these 2D layered MOF materials should be related to their sufficient interlayer spaces and redox-activity metal ions. Though some MOF-based supercapacitor electrode materials with high performances have been obtained, such materials are not yet present in large numbers. Specifically, layered Mn-based MOFs used as electrode materials for supercapacitors have not been reported.

In the present study, we successfully synthesized a layered Mn-based MOF $\left(\left[\mathrm{Mn}(\mathrm{tfbdc})\left(4,4^{\prime}-\mathrm{bpy}\right)\left(\mathrm{H}_{2} \mathrm{O}\right)_{2}\right], \quad \mathrm{Mn}-\mathrm{LMOF}\right.$; $\mathrm{H}_{2} \mathrm{tfbdc}=2,3,5,6$-tetrafluoroterephthalic acid, 4,4'-bpy $=4,4^{\prime}$ bipyridine) and investigated its electrochemical performances as an electrode material for supercapacitors for the first time. The Mn-LMOF electrodes displayed a high specific capacitance, a good cycling stability and an improved rate capability. Specific capacitances of 1098 and $1178 \mathrm{~F} \mathrm{~g}^{-1}$ were achieved in $1 \mathrm{M} \mathrm{KOH}$ and $1 \mathrm{M} \mathrm{LiOH}$ solution for the Mn-LMOF.

\section{Experimental}

\section{Materials synthesis}

Mn-LMOF was synthesized according to a previous report with some modifications. ${ }^{24}$ Moreover, 4,4'-bpy (0.0156 g, $0.10 \mathrm{mmol}$ ) and $\mathrm{H}_{2} \mathrm{tfbdc}(0.0476 \mathrm{~g}, 0.20 \mathrm{mmol})$ were dissolved in $10 \mathrm{~mL}$ water with stirring. Then, a $10 \mathrm{~mL}$ water solution of $\mathrm{Mn}(\mathrm{OAc})_{2} \cdot 4 \mathrm{H}_{2} \mathrm{O}(0.049 \mathrm{~g}, 0.20 \mathrm{mmol})$ was mixed with the above solution to obtain a colorless solution. This solution was allowed to stand at room temperature for evaporation, and colorless crystals of $\left[\mathrm{Mn}(\mathrm{tfbdc})\left(4,4^{\prime}-\mathrm{bpy}\right)\left(\mathrm{H}_{2} \mathrm{O}\right)_{2}\right]$ (Mn-LMOF) were collected after a few days.

\section{Material characterization}

Powder X-ray diffraction (XRD) patterns were recorded on an Xray diffractometer $(\mathrm{D} / \mathrm{max} 2500 \mathrm{PC}$, Rigaku) using $\mathrm{Cu}-\mathrm{K} \alpha$ radiation (1.5406 ̊). Fourier-transform infrared (FT-IR) spectral measurements were carried out on a Nicolet 460 spectrophotometer in the form of $\mathrm{KBr}$ pellets. Thermogravimetric analysis (TGA) experiments were performed on a Dupont thermal analyzer with a heating rate of $10{ }^{\circ} \mathrm{C} \mathrm{min}^{-1}$ from room temperature to $800{ }^{\circ} \mathrm{C}$ under nitrogen flow. The X-ray photoelectron spectrum (XPS) measurement was performed on an ESCALABMK II X-ray photoelectron spectrometer. A micromeritics pore analyzer (ASAP2010C) was used to measure the $\mathrm{N}_{2}$ sorption isotherm of the sample under continuous adsorption conditions at $77 \mathrm{~K}$. The sample was degassed at $50{ }^{\circ} \mathrm{C}$ for $15 \mathrm{~h}$ before measurements. The pore size, pore volume and surface area were determined by Barrett, Joyner, and Halenda (BJH) and Brunauer, Emmett, and Teller (BET) analyses. A Supra 55 field emission scanning electron microscopy (FESEM) system (Zeiss) was used to collect the FESEM images.

\section{Electrode preparation and electrochemical characterization}

The working electrode was made by mixing $75 \mathrm{wt} \%$ active material (Mn-LMOF), $15 \mathrm{wt} \%$ acetylene black, and $10 \mathrm{wt} \%$ polytetrafluoroethylene (PTFE) solution (60 wt\%) in ethanol and then coated onto the nickel foam $(1 \mathrm{~cm} \times 1 \mathrm{~cm})$ and pressed under $10 \mathrm{MPa}$. The electrodes were dried at $60{ }^{\circ} \mathrm{C}$ for $8 \mathrm{~h}$ under vacuum. The mass loading of the active material was about 2.0$4.6 \mathrm{mg} \mathrm{cm}^{-2}$.

Electrochemical measurements were performed on a CHI660D electrochemical workstation ( $\mathrm{CH}$ Instruments, Huake. Co., Beijing) in a $\mathrm{KOH}$ aqueous electrolyte $(1.0 \mathrm{M})$ or LiOH electrolyte $(1.0 \mathrm{M})$ using a three-electrode configuration, comprising a Pt foil counter electrode and a saturated calomel electrode (SCE) as the reference electrode and working electrode. Cyclic voltammetry $(\mathrm{CV})$ was performed at scan rates of 2$200 \mathrm{mV} \mathrm{s}^{-1}$ in the potential range of -0.2 to $0.6 \mathrm{~V}$. Galvanostatic charge-discharge (GCD) curves were conducted within the potential window of $0-0.5 \mathrm{~V}$ at different constant current density. The cycle life tests were carried out by galvanostatic charge-discharge measurements with a constant current density of $2 \mathrm{~A} \mathrm{~g}^{-1}$ for 2000 cycles. Electrochemical impedance spectroscopy (EIS) data were collected in the frequency range from $0.01 \mathrm{~Hz}$ to $100 \mathrm{kHz}$ at an open-circuit potential with an amplitude of $5 \mathrm{mV}$.

The specific capacitance of the Mn-LMOF electrode $\left(C, \mathrm{~F} \mathrm{~g}^{-1}\right)$ can be calculated by the following equation:

$$
C=\frac{I t}{m \Delta V}
$$

where $I$ is the constant current (A), $m, t$, and $\Delta V$ are the mass of the Mn-LMOF electroactive material $(\mathrm{g})$, the discharge time $(\mathrm{s})$, and the potential window $(\mathrm{V})$, respectively. 


\section{Results and discussion}

\section{Characterization of Mn-LMOF}

The powder X-ray diffraction (XRD) pattern of as-synthesized Mn-LMOF is shown in Fig. 1a. It can be seen from Fig. 1a that the XRD pattern of as-synthesized product agrees with the simulated pattern based on the single-crystal data of Mn-LMOF (CCDC 733870), ${ }^{24}$ indicating that the as-synthesized Mn-LMOF has high purity. A Fourier-transform infrared (FT-IR) spectrum test was used to further characterize the structure of assynthesized Mn-LMOF. As can be seen in Fig. 1b, an evidently strong peak at $3461 \mathrm{~cm}^{-1}$ is ascribed to $\nu(\mathrm{OH})$ of coordinated water molecules; moreover, two strong peaks at 1605 and 1386 $\mathrm{cm}^{-1}$ are attributed to $\nu_{\text {as }}(\mathrm{OCO})$ and $\nu_{\mathrm{s}}(\mathrm{OCO})$ stretching modes of tetrafluoroterephthalate anions, respectively; a $\nu(\mathrm{C}-\mathrm{H})$ bent vibration peak from 4,4'-bipy appears at $806 \mathrm{~cm}^{-1} \cdot{ }^{24}$ The existence of $\mathrm{C}, \mathrm{N}, \mathrm{O}, \mathrm{F}$, and Mn elements was verified by the XPS spectrum of the as-synthesized Mn-LMOF, as shown in Fig. 2a. As presented in the high-resolution XPS spectra (Fig. 2b-f), the peaks located at 285.08, 399.58, 531.88, 687.58, and 641.48 and $654.18 \mathrm{eV}$ belong to the $\mathrm{C} 1 \mathrm{~s}, \mathrm{~N} 1 \mathrm{~s}, \mathrm{O} 1 \mathrm{~s}, \mathrm{~F} 1 \mathrm{~s}$, and Mn $2 \mathrm{p}_{3 / 2}$ and $2 \mathrm{p}_{1 / 2}$ orbits, respectively. These values are in accord with the values reported in the literature. ${ }^{58}$

Fig. S1 $\dagger$ shows the TGA curve of the Mn-LMOF sample. Between $182^{\circ} \mathrm{C}$ and $240{ }^{\circ} \mathrm{C}$, the weight loss is due to the removal of two molecules of water (calcd $7.46 \%$, found $7.02 \%$ ), while the weight loss from $249{ }^{\circ} \mathrm{C}$ to $349^{\circ} \mathrm{C}$ corresponds to the loss of the $4,4^{\prime}$-bpy molecule.

The morphology and microstructure of the as-synthesized Mn-LMOF after grinding for $2 \mathrm{~h}$ were examined by FESEM. As observed in Fig. 3a, the Mn-LMOF sample is built up of microsized particles; when seen from the higher magnification SEM image (Fig. 3b), these particles also consist of nanosheets and nanoparticles. Nanosheets and nanoparticles shorten the transmission distance of electrons/ions, which helps to increase the capacitance of the Mn-LMOF electrode.

Mn-LMOF is a two-dimensional (2D) layered coordination polymer with cavities, as shown in Fig. 4a. The 2D layers are formed by $\mathrm{Mn}$ (II) ions bridging with tetrafluoroterephthalate anions and 4,4'-bpy molecules. These $2 \mathrm{D}$ layers are further linked by the interaction of hydrogen bonding, resulting in the formation of a three-dimensional (3D) supramolecular framework, as displayed in Fig. S2. $\uparrow$ The presence of hydrogen bonds
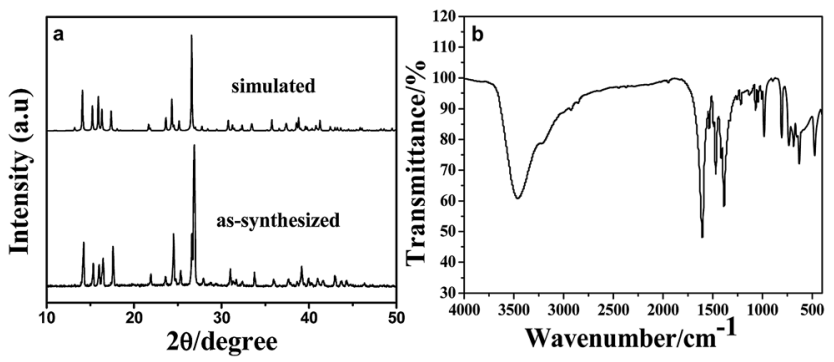

Fig. 1 (a) XRD pattern of as-synthesized Mn-LMOF and the simulated pattern based on the crystal data of Mn-LMOF (b) FT-IR spectrum of the Mn-LMOF.
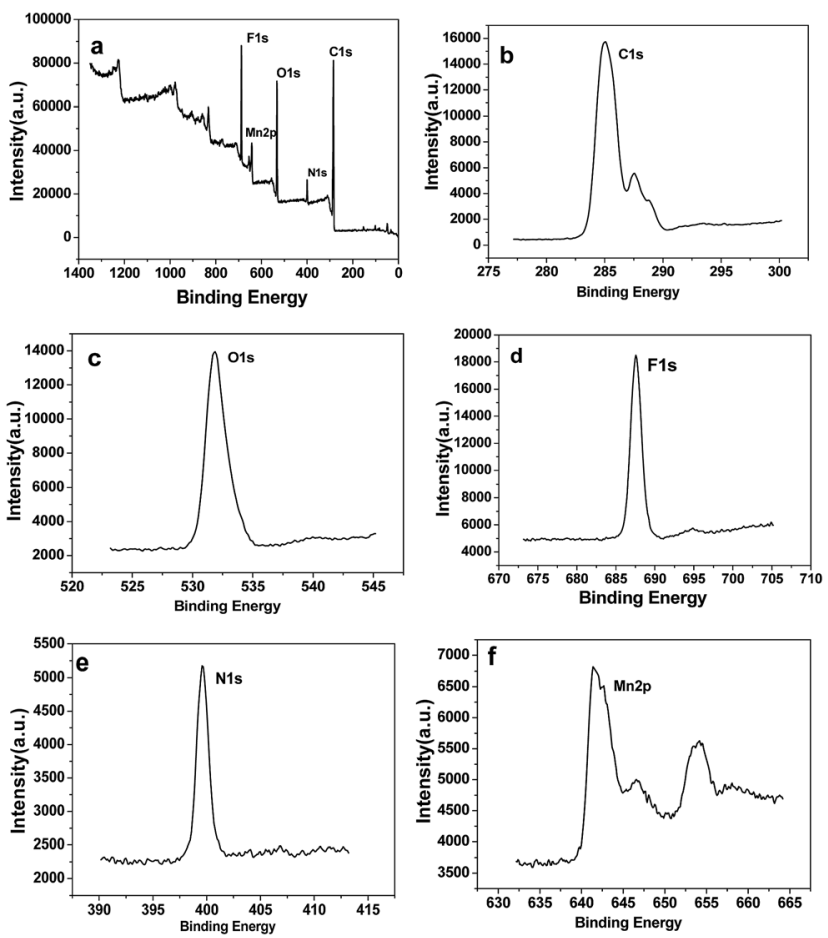

Fig. 2 (a) XPS survey spectrum of the Mn-LMOF. (b-f) XPS core level spectra of $C 1 s, O 1 s, F 1 s, N$ s, and Mn 2p of the Mn-LMOF.

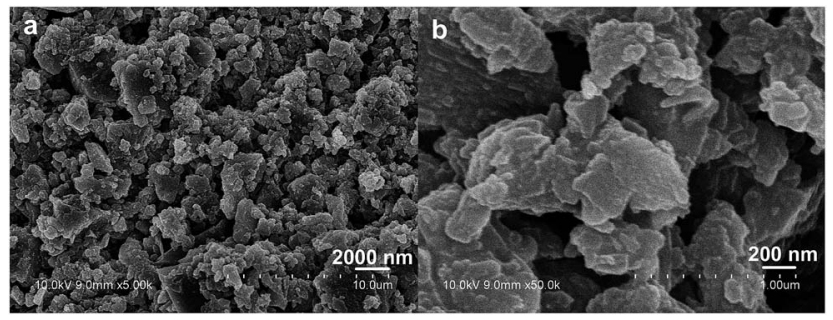

Fig. 3 (a) Low-magnification and (b) high-magnification SEM images of as-synthesized Mn-LMOF after grinding for $2 \mathrm{~h}$.

increases the stability of the framework's 3D structure. Such interspace must be convenient for electrolyte diffusion and storage. The surface area, pore size distribution, and pore volume of the Mn-LMOF after grinding for $2 \mathrm{~h}$ were analyzed by nitrogen adsorption-desorption techniques. The single point

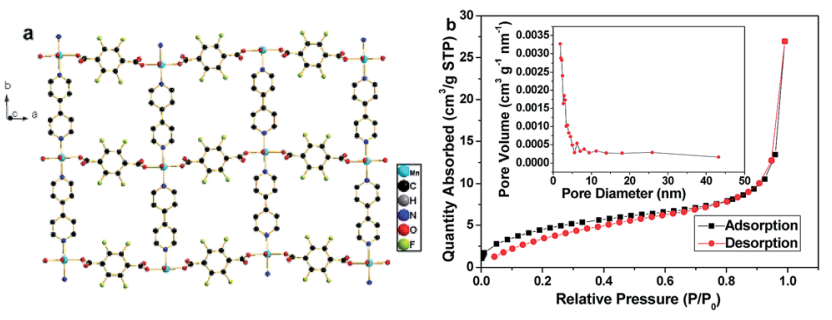

Fig. 4 (a) 2D view of Mn-LMOF. (b) $\mathrm{N}_{2}$ adsorption-desorption isotherm of as-synthesized Mn-LMOF after grinding for $2 \mathrm{~h}$, and the inset represents the pore size distribution curve. 
adsorption total pore volume of pores and the BET surface area are $0.0167 \mathrm{~cm}^{3} \mathrm{~g}^{-1}$ and $17.08 \mathrm{~m}^{2} \mathrm{~g}^{-1}$, respectively. The $\mathrm{N}_{2}$ isotherm of the Mn-LMOF belongs to hybrid type III and IV, as presented in Fig. 4b. The hysteresis belongs to type H1. The pore size distribution can be obtained by the Barrett-JoynerHalenda (BJH) method, which is displayed in the inset of Fig. 4b. The pore distribution with micropores, mesopores and macropores is observed. The maximum pore distribution appears at around $1.8 \mathrm{~nm}$. The micropores should be ascribed to the cavities of the layered Mn-LMOF itself, while macropores and mesopores should originate from interparticle pores. Usually, high micro/mesoporosity is associated with high capacitance value, ${ }^{38,59}$ and hence the Mn-LMOF might act as a potentially high performance electrode material for supercapacitors.

\section{Electrochemical properties}

The electrochemical performances of the Mn-LMOF as an electrode material of supercapacitors were evaluated by cyclic voltammetry $(\mathrm{CV})$ and galvanostatic charge-discharge in a three electrode system. The CV curve of the Mn-LMOF electrode at the scan rate of $2 \mathrm{mV} \mathrm{s}^{-1}$ in $1 \mathrm{M} \mathrm{KOH}$ solution is displayed in the inset of Fig. 5a. As can be clearly seen in the curve, a pair of redox peaks appears at around 0.3 and $0.46 \mathrm{~V}$, which might be originating from the changing between manganese ions of different valence states, and indicates that the pseudocapacitance mainly results from the surface redox reactions. Similar to the reported MOF-based electrode materials, such as $\left\{\left[\mathrm{Co}(\mathrm{Hmt})(\mathrm{tfbdc})\left(\mathrm{H}_{2} \mathrm{O}\right)_{2}\right] \cdot\left(\mathrm{H}_{2} \mathrm{O}\right)_{2}\right\}_{n}{ }^{38}$ and $\mathrm{Ni}_{3}(\mathrm{btc})_{2} \cdot 12 \mathrm{H}_{2} \mathrm{O},{ }^{45}$ this conversion process may be expressed by the following equations:

$$
\begin{aligned}
& \mathrm{Mn}(\mathrm{II})_{\mathrm{s}}+\mathrm{OH}^{-} \leftrightarrow \mathrm{Mn}(\mathrm{II})(\mathrm{OH})_{\mathrm{ad}}+\mathrm{e}^{-} \\
& \operatorname{Mn}(\mathrm{II})(\mathrm{OH})_{\mathrm{ad}} \leftrightarrow \operatorname{Mn}(\mathrm{III})(\mathrm{OH})_{\mathrm{ad}}+\mathrm{e}^{-}
\end{aligned}
$$

When the scan rate increases from 2 to $60 \mathrm{mV} \mathrm{s}^{-1}$, as shown in Fig. 5a, the peak separation between the oxidation and reduction peaks also increases. This increase should be relative to the increase of the internal resistance of the electrode. ${ }^{38}$ As the scan rate increases to $80-200 \mathrm{mV} \mathrm{s}^{-1}$, oxidation peaks disappear, indicating that the redox process of the electrode controlled by diffusion might be transferred to the control process of charge transfer or hybrid control process of diffusion and charge transfer.

The charge-discharge profiles of the Mn-LMOF electrode were further studied in $1 \mathrm{M} \mathrm{KOH}$ solution within the potential window of 0 to $0.45 \mathrm{~V}$ at different current densities (Fig. 6a). Note, each discharge curve has a slope, which reveals that the electrode has a pseudocapacitive behavior originating from the redox reactions. According to the discharge profiles, the specific capacitances of the Mn-LMOF electrode $\left(C, \mathrm{~F} \mathrm{~g}^{-1}\right)$ are shown in Fig. 6c. The Mn-LMOF electrode has a high specific capacitance of $1098 \mathrm{~F} \mathrm{~g}^{-1}$ at a current density of $1 \mathrm{~A} \mathrm{~g}^{-1}$. Even at $20 \mathrm{~A} \mathrm{~g}^{-1}$, the specific capacitance can still be about $396 \mathrm{~F} \mathrm{~g}^{-1}$, showing an excellent rate capability. Compared with the MOF/coordination polymer based electrode materials reported recently and $\mathrm{MnO}_{x}$ based electrode materials (Table $\mathrm{S} 1 \dagger$ ), the specific capacitance of $1098 \mathrm{~F} \mathrm{~g}^{-1}$ is also higher. As observed in Fig. 6c, the specific capacitance will decrease with the current density increasing, which should be attributed to the decrease in effective interaction between electrolyte ions and the electrode..$^{\mathbf{3 8 0}}$

To evaluate the cycle stability of the Mn-LMOF electrode, 2000 cycles of charge-discharge were measured at a current density of $2 \mathrm{~A} \mathrm{~g}^{-1}$. As presented in Fig. 6d, the Mn-LMOF can still retain $820 \mathrm{~F} \mathrm{~g}^{-1}$ (92.6\% of the initial specific capacitance) after 2000 cycles. Fig. S3† displays the charge-discharge curves of the Mn-LMOF for the first three cycles at a current density of 3 $\mathrm{A} \mathrm{g}^{-1}$. Each curve has similar time-potential response behaviour, further verifying the excellent electrochemical reversibility. After the testing of 1000 cycles, the FT-IR spectrum and XRD pattern of the Mn-LMOF electrode were measured (Fig. S4 and $\mathrm{S} 5 \dagger$ ). In comparison to the original Mn-LMOF electrode the band at $1632 \mathrm{~cm}^{-1}$ belonging to $\nu_{\text {as }}(\mathrm{OCO})$ still exists in the FT-IR spectrum after 1000 cycles, showing the conversion reversibility of $\mathrm{tfbdc}^{2-}$ ions. Diffraction peak positions of the Mn-LMOF electrode after 1000 cycles are nearly the same as that of the bare electrode containing Mn-LMOF, polytetrafluoroethylene (PTFE) and acetylene black. These facts further reveal that the Mn-LMOF electrode has good cycling stability.
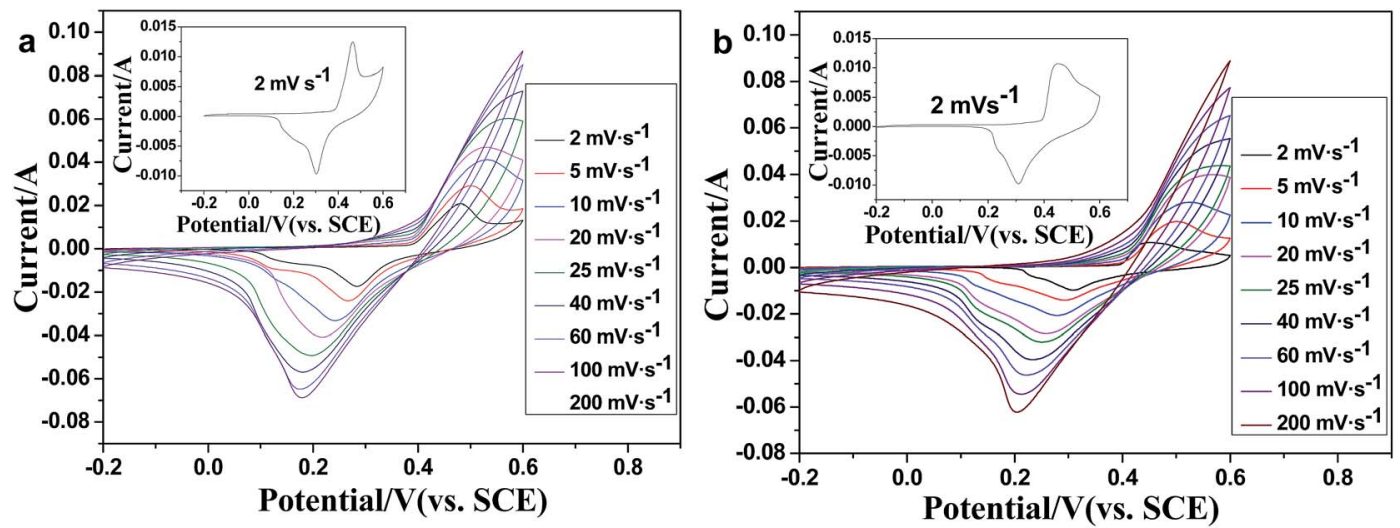

Fig. $5 \mathrm{CV}$ curves of the Mn-LMOF electrode at sweep rates from 2 to $200 \mathrm{mV} \mathrm{s}^{-1}$ in (a) $1 \mathrm{M} \mathrm{KOH}$ and (b) $1 \mathrm{M} \mathrm{LiOH}$ solution. 

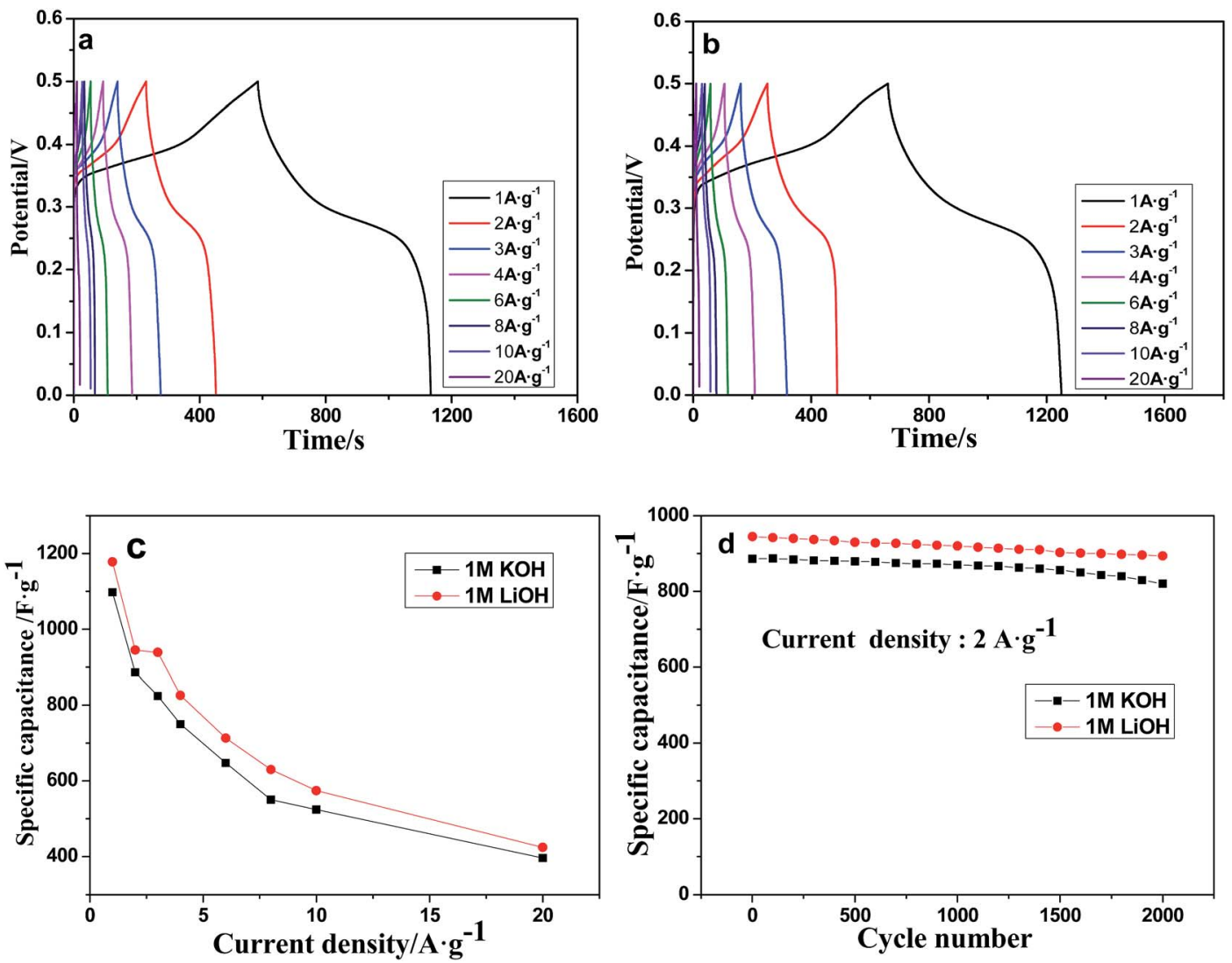

Fig. 6 The charge-discharge curves of the Mn-LMOF electrode at different current densities (a) $1 \mathrm{M} \mathrm{KOH} \mathrm{(b)} 1 \mathrm{M} \mathrm{LiOH}$. (c) The curves of specific capacitance versus current density in $1 \mathrm{M} \mathrm{KOH}$ and $1 \mathrm{M} \mathrm{LiOH}$. (d) Cycle life diagrams of the $\mathrm{Mn}-\mathrm{LMOF}$ electrode at $2 \mathrm{Ag}^{-1}$ in $1 \mathrm{M} \mathrm{KOH}^{\mathrm{K}}$ and $1 \mathrm{M}$ $\mathrm{LiOH}$.

In the case of the supercapacitor using $1 \mathrm{M} \mathrm{LiOH}$ electrolyte, the CV curves and galvanostatic charge-discharge profiles, rate capability and cycle stability are similar to that of a supercapacitor using $1 \mathrm{M} \mathrm{KOH}$ (Fig. 5b, 6b-d and S6 + ); the specific capacitances are $1178,945,939,826,713,630,574$ and $424 \mathrm{~F} \mathrm{~g}^{-1}$ at different current densities of 1, 2, 3, 4, 6, 8, 10 and $20 \mathrm{~A} \mathrm{~g}^{-1}$, respectively, slightly higher than those found when using $1 \mathrm{M}$ $\mathrm{KOH}$. After 2000 cycles, the specific capacitance remains at $94.6 \%$ of the initial capacitance.

Electrochemical impedance spectroscopy (EIS) measurements were performed to further understand the electrochemical performances, and the results are presented in Fig. 7. In the high frequency range of the plot, the internal resistance $\left(R_{\mathrm{s}}\right)$ includes intrinsic resistance of the active material $(\mathrm{Mn}-$ LMOF), the ionic resistance of the electrolyte, and the contact resistance between the substrate and the active material. ${ }^{61} R_{\mathrm{s}}$ values are $1.86 \Omega$ for $1 \mathrm{M} \mathrm{KOH}$ and $1.96 \Omega$ for $1 \mathrm{M} \mathrm{LiOH}$. The values are comparable to that of the reported Co-LMOF electrode. ${ }^{38}$ The semicircle observed in the range of high frequency is related to charge transfer and surface resistance. Almost the same semicircles are observed in the plots of the $1 \mathrm{M} \mathrm{KOH}$ and $1 \mathrm{M} \mathrm{LiOH}$ electrolytes, indicating that the charge transfer resistances $\left(R_{\mathrm{ct}}\right)$ are almost the same in the two electrolytes. The unapparent semicircle reveals a low $R_{\mathrm{ct}}$. At the low frequency region, the phase angle of the plot for the $1 \mathrm{M} \mathrm{LiOH}$ electrolyte is slightly larger than that for the $1 \mathrm{M} \mathrm{KOH}$ electrolyte, and the length of the Warburg line is shorter for the $1 \mathrm{M} \mathrm{LiOH}$ electrolyte, indicating that the diffusion impedance of the $1 \mathrm{M} \mathrm{LiOH}$ electrolyte is smaller, and the diffusion velocity of $\mathrm{Li}^{+}$ion is faster. ${ }^{62}$ This result may be ascribed to the fact that the $\mathrm{Li}^{+}$ion has a smaller radius.

The Mn-LMOF as a supercapacitor electrode material exhibits an excellent capacitive performance, which can be ascribed to the layered structure of Mn-LMOF, the Mn-LMOF

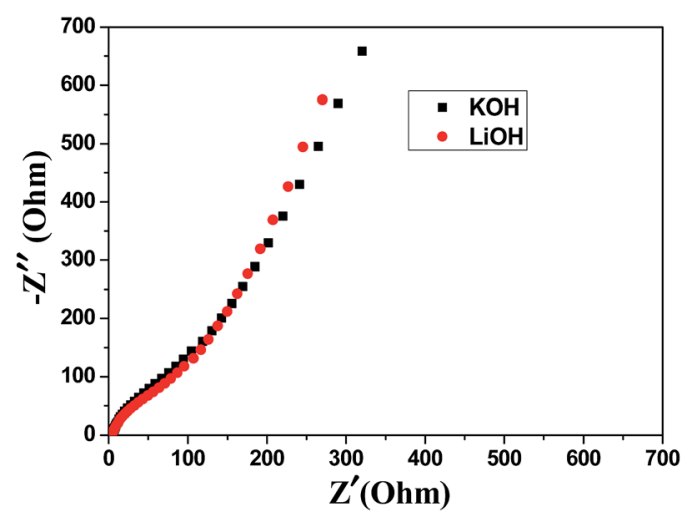

Fig. 7 Nyquist plots of the Mn-LMOF electrode in $1 \mathrm{M} \mathrm{KOH}$ and $1 \mathrm{M}$ $\mathrm{LiOH}$. 
nano-sized particles and the micro/mesoporosity of this material. First, the layered structure of Mn-LMOF can provide both metal ions involved in the faradaic reaction and enough interspaces for the storage and diffusion of the electrolyte. Second, the Mn-LMOF nano-sized particles can shorten the diffusion distance of the electrolyte and have more active sites for the faradaic reaction. In addition, the micro/mesoporosity is also beneficial for the transport of the electrolyte.

\section{Conclusions}

In summary, the Mn-LMOF electrode exhibits good cycling stability and high specific capacitance in two alkaline electrolytes. In the case of $1 \mathrm{M}$ LiOH solution, a maximum specific capacitance of $1178 \mathrm{~F} \mathrm{~g}^{-1}$ is obtained at $1 \mathrm{~A} \mathrm{~g}^{-1}$, and the capacitance retention is $94.6 \%$ after 2000 cycles; the values are slightly higher (1098 $\mathrm{F} \mathrm{g}^{-1}, 92.6 \%$ ) in the case of $1 \mathrm{M} \mathrm{KOH}$ solution. This is the first report of a layered Mn-based metalorganic framework being applied as a supercapacitor electrode material. Its excellent electrochemical performance and simple synthetic procedure indicate that the Mn-LMOF material with nanosheets and nanoparticle morphologies is a promising electrode material for supercapacitors. The results will encourage us to synthesize more MOFs based electrode materials with layered structures.

\section{Acknowledgements}

We thank the National Natural Science Foundation of China (No. 20971060), the Project Funded by the Advanced Catalysis and Green Manufacturing Collaborative Innovation Center, the Natural Science Research Key Project of Jiangsu Colleges and Universities (No. 16KJA430005), and the Natural Science Foundation of the State Key Laboratory of Coordination Chemistry for the financial support.

\section{Notes and references}

1 M. Winter and R. J. Brodd, Chem. Rev., 2004, 104, 4245.

2 A. Burke, J. Power Sources, 2000, 91, 37.

3 R. Kötz and M. Carlen, Electrochim. Acta, 2000, 45, 2483.

4 G. P. Wang, L. Zhang and J. J. Zhang, Chem. Soc. Rev., 2012, 41, 797.

5 P. Soudan, J. Gaudet, D. Guay, D. Bélanger and R. Schulz, Chem. Mater., 2002, 14, 1210.

6 C. Z. Yuan, H. B. Wu, Y. Xie and X. W. Lou, Angew. Chem., Int. Ed., 2014, 53, 1488.

7 H.-W. Chang, Y.-R. Lu, J.-L. Chen, C.-L. Chen, J.-F. Lee, J.-M. Chen, Y.-C. Tsai, P.-H. Yeh, W.-C. Chou and C.-L. Dong, Phys. Chem. Chem. Phys., 2016, 18, 18705.

8 W. F. Wei, X. W. Cui, W. X. Chen and D. G. Ivey, Chem. Soc. Rev., 2011, 40, 1697.

9 J. Y. Wang, H. J. Tang, H. Ren, R. B. Yu, J. Qi, D. Mao, H. J. Zhao and D. Wang, Adv. Sci., 2014, 1, 1719.

10 F. Y. Yang, M. S. Zhao, Q. J. Sun and Y. Q. Qiao, RSC Adv., 2015, 5, 9843.
11 R. T. Vinny, K. Chaitra, K. Venkatesh, N. Nagaraju and N. Kathyayini, J. Power Sources, 2016, 309, 212.

12 S. A. Ansari, N. Parveen, T. H. Han, M. O. Ansari and M. H. Cho, Phys. Chem. Chem. Phys., 2016, 18, 9053.

13 G. H. Yu, L. B. Hu, N. Liu, H. L. Wang, M. Vosgueritchian, Y. Yang, Y. Cui and Z. N. Bao, Nano Lett., 2011, 11, 4438.

14 H. Furukawa, K. E. Cordova, M. O'Keeffe and O. M. Yaghi, Science, 2013, 341, 1230444.

15 N. Stock and S. Biswas, Chem. Rev., 2012, 112, 933.

16 K. Ohara, M. Kawano, Y. Inokuma and M. Fujita, J. Am. Chem. Soc., 2010, 132, 30.

17 P. García-garcía, M. Müller and A. Corma, Chem. Sci., 2014, 5, 2979.

18 A. Dhakshinamoorthy, A. M. Asiric and H. Garcia, Chem. Soc. Rev., 2015, 44, 1922.

19 H. Deng, C. J. Doonan, H. Furukawa, R. B. Ferreira, J. Towne, C. B. Knobler, B. Wang and O. M. Yaghi, Science, 2010, 327, 846.

20 E. Tsivion, J. A. Mason, M. I. Gonzalez, J. R. Longacd and M. Headgordon, Chem. Sci., 2016, 7, 4503.

21 Z. Zhong, L. R. Zhang, Y. Z. Li, Z. J. Guo and H. G. Zheng, J. Am. Chem. Soc., 2011, 133, 4172.

22 O. S. Wenger, Chem. Rev., 2013, 113, 3686.

23 Y. F. Li, A. Y. Pang, C. J. Wang and M. Wei, J. Mater. Chem., 2011, 21, 17259.

24 Q. Liu, L. L. Yu, Y. Wang, Y. Z. Ji, J. Horvat, M. L. Cheng, X. Y. Jia and G. X. Wang, Inorg. Chem., 2013, 52, 2817.

25 C. D. Shi, Q. H. Xia, X. Xue, Q. Liu and H. J. Liu, RSC Adv., 2016, 6, 4442.

26 H. Y. Wang, Y. Wu, C. F. Leong, D. M. D'Alessandro and J. L. Zuo, Inorg. Chem., 2015, 54, 10766.

27 A. Morozan and F. Jaouen, Energy Environ. Sci., 2012, 5, 9269.

28 F. S. Ke, Y. S. Wu and H. J. Deng, J. Solid State Chem., 2015, 223, 109.

29 L. Wang, Y. Han, X. Feng, J. Zhou, P. Qi and B. Wang, Coord. Chem. Rev., 2016, 307, 361.

30 S. L. Li and Q. Xu, Energy Environ. Sci., 2013, 6, 1656.

31 H. Pang, F. Gao, Q. Chen, R. M. Liu and Q. Y. Lu, Dalton Trans., 2012, 41, 5862.

32 B. Liu, H. Shioyama, T. Akita and Q. Xu, J. Am. Chem. Soc, 2008, 130, 5390.

33 R. Díaz, M. Gisela Orcajo, J. A. Botas, G. Calleja and J. Palma, Mater. Lett., 2012, 68, 126.

34 D. Y. Lee, S. J. Yoon, N. K. Shrestha, S. H. Lee, H. Ahn and S. H. Han, Microporous Mesoporous Mater., 2012, 153, 163.

35 D. Y. Lee, D. V. Shinde, E. K. Kim, W. Lee, W. I. Oh, N. K. Shrestha, J. K. Lee and S. H. Han, Microporous Mesoporous Mater., 2013, 171, 53.

36 H. Yu, D. Xu and Q. Xu, Chem. Commun., 2015, 51, 13197. 37 L. Wang, X. Feng, L. Ren, Q. Piao, J. Zhong, Y. Wang, H. Li, Y. Chen and B. Wang, J. Am. Chem. Soc., 2015, 137, 4920.

38 X. Liu, C. Shi, C. Zhai, M. Cheng, Q. Liu and G. Wang, ACS Appl. Mater. Interfaces, 2016, 8, 4585.

39 J. Yang, Z. H. Ma, W. X. Gao and M. Wei, Chem.-Eur. J., 2016, 23, 631.

40 K. M. Choi, H. M. Jeong, J. H. Park, B. Y. Zhang, J. K. Kang and O. M. Yaghi, ACS Nano, 2014, 8, 7451. 
41 Y. Tan, W. Zhang, Y. Gao, J. Wu and B. Tang, RSC Adv., 2015, 5, 17601.

42 D. Zhang, H. Shi, R. Zhang, Z. Zhang, N. Wang, J. Li, B. Yuan, H. Bai and J. Zhang, RSC Adv., 2015, 5, 58772.

43 J. Yang, P. Xiong, C. Zheng, H. Qiu and M. Wei, J. Mater. Chem. A, 2104, 2, 16640.

44 J. Yang, C. Zheng, P. Xiong, Y. Li and M. Wei, J. Mater. Chem. A, 2014, 2, 19005.

45 L. Kang, S. X. Sun, L. B. Kong, J. W. Lang and Y. C. Luo, Chin. Chem. Lett., 2014, 25, 957.

46 C. Qu, Y. Jiao, B. Zhao, D. Chen, R. Zou, K. S. Walton and M. Liu, Nano Energy, 2016, 26, 66.

47 P. Wen, P. Gong, J. Sun, J. Wang and S. Yang, J. Mater. Chem. A, 2015, 3, 13874.

48 Y. Yan, P. Gu, S. S. Zheng, M. B. Zheng, H. Pang and H. G. Xue, J. Mater. Chem. A, 2016, 4, 19078.

49 Y. Jiao, J. Pei, D. H. Chen, C. S. Yan, Y. Y. Hu, Q. Zhang and G. Chen, J. Mater. Chem. A, 2017, 5, 1094.

50 D. Sheberla, J. C. Bachman, J. S. Elias, C. J. Sun, Y. Shao-Horn and M. Dinca, Nat. Mater., 2017, 16, 220.

51 Y. J. Zhou, Z. M. Mao, W. Wang, Z. K. Yang and X. Liu, ACS Appl. Mater. Interfaces, 2016, 8, 28904.

52 Y. Gong, J. Li, P. G. Jiang, Q. F. Li and J. H. Lin, Dalton Trans., 2013, 42, 1603.
53 M. Du, M. Chen, X. G. Yang, J. Wen, X. Wang, S. M. Fang and C. S. Liu, J. Mater. Chem. A, 2014, 2, 9828.

54 Q. Liu, X. Liu, C. Shi, Y. Zhang, X. Feng, M. L. Cheng, S. Su and J. Gu, Dalton Trans., 2015, 44, 19175.

55 A. Ehsani, J. Khodayari, M. Hadi, H. Mohammad Shiri and H. Mostaanzadeh, Ionics, 2017, 23, 131.

56 Y. Zhang, B. Lin, Y. Sun, X. Zhang, H. Yang and J. Wang, RSC Adv., 2015, 5, 58100.

57 N. Campagnol, R. Romero-Vara, W. Deleu, L. Stappers, K. Binnemans, D. E. Devos and J. Fransaer, ChemElectroChem, 2014, 1, 1182.

58 S. Liu, D. Wang and S. Pan, Analysis of X-ray Photoelectron Spectroscopy, Science Press, Beijing, 1998.

59 K. Deori, S. K. Ujjain, R. K. Sharma and S. Deka, ACS Appl. Mater. Interfaces, 2013, 5, 10665.

60 T. Yan, Z. J. Li, R. Y. Li, Q. Ning, H. Kong, Y. L. Niu and J. K. Liu, J. Mater. Chem., 2012, 22, 23587.

61 B. E. Conway, Electrochemical Supercapacitors: Scientific Fundamentals and Technological Applications, Springer Science \& Business Media, 2013.

62 R. B. Rakhi, B. Ahmed, D. Anjum and H. N. Alshareef, ACS Appl. Mater. Interfaces, 2016, 8, 18806. 